\title{
Double layer theory and compressibility of clays
}

\author{
A. SRIDHARAN and M. S. JAYADEVA (1982). Géotechnique 32, No. 2, 133-144
}

\section{Mr P. Delage and Professor G. I Lefebvre, Université de Sherbrooke, Québec}

The relationship between clay particles and the macroscopic geotechnical behaviour of the soil is an important topic which needs investigation. Schofield (1946) used the double layer theory to determine the swelling pressure of clays. More recent work by Chaussidon \& Henin (1962), Quirk (1978) and Tessier \& Quirk (1979) has shown that the swelling of clays involves discontinuities or pores, generally in the size range of $1 \mu \mathrm{m}$. Those workers concluded that such an order of magnitude could result not only from the intervention of a double layer phenomenon.

By observing discrepancies between permeabilities calculated from the Kozeny-Carman equation and measured on various pure clays submitted to consolidation, Olsen (1962) concluded that only unequal pore sizes could account for those discrepancies. He attributed those different pore sizes to the existence of clusters and domains in the soil. Pusch $(1970,1973)$ and Yong \& Sheeran (1973) confirmed these conclusions, showing that in many soils, clay structure is constituted by aggregation of particles, generally defining two types of pore-intra-aggregate and inter-aggregate, the latter involving large distances between the structural units. This point of view was confirmed by scanning electron microscope observations on sensitive Champlain clays (Delage, Tessier \& Marcel-Audiguier, 1982), which showed the existence of $1 \mu \mathrm{m}$ wide inter-aggregate pores. In another study (Delage \& Lefebvre, 1983), where scanning electron microscopy was coupled with mercury intrusion, it was shown that the compressibility of the Champlain clay studied was governed by inter-aggregate pore collapses. The distances involved -in the $1 \mu \mathrm{m}$ range could not be governed by double layer phenomena. We therefore think that in many clays or clayey soils the relation between the elementary clay platelet and the macroscopic behaviour during compressibility would be difficult to investigate without consideration of the intermediate structure levels, which involve large discontinuities not governed by double layer phenomena.

\section{RFFFRFNCES}

Chaussidon, J. \& Henin, S. (1962). Au sujet des différents états de l'eau dans les matériaux argileux. C. R. Hebd. Séanc. Acad. Sci., Paris 254, 1472-1474.

Delage, P., Tessier, D. \& Marcel-Audiguier, M. (1982). Use of the cryoscan apparatus for observation of freeze-fractured planes of a sensitive Quebec clay in scanning electron microscopy. Can. Geotech. J. 19, 111-114.

Delage, P. \& Lefebvre, G. (1983). Study of the structure of a sensitive Champlain clay and of its evolution during consolidation. Can. Geotech. J.

Olsen, H. W. (1962). Hydraulic flow through saturated clays. Clays Clay Miner. 11, 131-161.

Pusch, R. (1970). Microstructural changes in soft quick clay at failure. Can. Geotech. J. 7, 1-7.

Pusch, R. (1973). Influence of salinity and organic matter on the formation of clay microstructure. Proceedings of international symposium on soil structure, pp 161173. Gothenburg: Swedish Geotechnical Society.

Quirk, J. P. (1978). Some physico-chemical aspects of soil structural stability-a review. In Modification of soil structure (ed. W. W. Emerson et al.). New York: Wiley.

Schofield, R. K. (1946). Ionic forces in thick films of liquid between charged surfaces. Trans. Faraday Soc. 42B, 219.

Tessier, D. \& Quirk, J. P. (1979). Sur l'apport de la microscopie électronique dans la connaissance $\mathrm{du}$ gonflement des sols argileux C. R. Hebd. Séanc. Acad. Sci., Paris 288, 1375-1378.

Yong, R. N. \& Sheeran, D. E. (1973). Fabric unit interaction and soil behaviour. Proceedings of international symposium on soil structure, pp 176-183. Gothenburg: Swedish Geotechnical Society.

Mr B. R. Srinivasa Murthy and Professor T. S. Nagaraj, Indian Institute of Science, Bangalore

The compressibility of clays will depend on the electrolyte concentration, valency of the cation, temperature and dielectric constant of the pore fluid. There is no ambiguity in the values of temperature and dielectric constant to be chosen for the computations proposed by the Authors. However, the appropriate values of electrolyte concentration and valency to be chosen, so as to enhance the practical application of the analysis to field conditions, are a matter for consideration. 
In specifying the soil solution with any precision, Bolt \& Bruggenwert (1976) stated that in normal soil systems the soil solution at field capacity is around $0.01 \mathrm{~mol}$ in total electrolyte concentration. They also stated that the soil solution roughly consists of equal amounts of monovalent and divalent cations. Hence we have used values of $n=0.01 \mathrm{M}$ and $v=1.5$ in the Authors' analysis for computing the compressibility relationship.

The resulting interrelationship for the three clays considered by the Authors within the working stress range of $0.4-10 \mathrm{~kg} / \mathrm{cm}^{2}$ can be expressed in two forms.

(a) A linearized relation between $\log _{10} d$ and $\log _{10} p$, with a correlation coefficient of 0.994 , can be expressed as

$$
\log _{10} d=1.391-0.4366 \log _{10} p
$$

The instantaneous slope of the $d-\log _{10} p$ plot is

$$
\frac{\mathrm{d}(d)}{\mathrm{d}\left(\log _{10} p\right)}=-d
$$

and the compression index $C_{\mathrm{c}}$ is

$$
\frac{\mathrm{d}(e)}{\mathrm{d}\left(\log _{10} p\right)}=e=G \gamma_{\mathrm{w}} S d \times 10^{-4}
$$

(b) A linearized relation between $d$ and $\log _{10} p$, with a correlation coefficient of 0.992 , can be expressed as

$$
\begin{gathered}
d=25.67-18.86 \log _{10} p \\
\frac{\mathrm{d}(d)}{\mathrm{d}\left(\log _{10} p\right)}=-18.86 \\
C_{c}=\frac{\mathrm{d}(e)}{\mathrm{d}\left(\log _{10} p\right)}=18.86 G \gamma_{\mathrm{w}} S \times 10^{-4}
\end{gathered}
$$

Both $d-\log _{10} p$ and $\log _{10} d-\log _{10} p$ plots can be approximated to linear relationships with nearly the same degree of correlation. This might be the reason for practically viable different empirical relations for $C_{\mathrm{c}}$ in terms of liquid limit water content $w_{L}$ or natural void ratio $e$.

In the literature attempts have been made to relate the specific surface $S$ with the liquid limit water content of the soil $w_{L}$. Farrar \& Coleman (1967) give

$$
S=-14+1.48 w_{\mathrm{L}}
$$

where $S$ is in $\mathrm{m}^{2} / \mathrm{g}$ and $w_{\mathrm{L}}$ is a percentage, with a correlation coefficient of 0.91 . We have used this to explore the possibility of expressing equation (4) in terms of parameters which can be measured easily. On substitution of equation (5) into equation (4) and simplification, equation (4) reduces to

$$
C_{\mathrm{c}}=0.00754\left(w_{\mathrm{L}}-9 \cdot 46\right)
$$

This is nearly the same as Skempton's (1944) equation

$$
C_{\mathrm{c}}=0.007\left(w_{\mathrm{L}}-10\right)
$$

Using equation (5), equation (2) can be written as

$$
C_{\mathrm{c}}=0.0092\left(w_{\mathrm{L}}-9.46\right) \times 10^{-0.4366 \log _{10} p}
$$

For $p=1.58 \mathrm{~kg} / \mathrm{cm}^{2}$, equation (8) reduces to equation (6). It is clear from equation (8) that, although $C_{\mathrm{c}}$ is a function of $e$ and independent of soil type as shown by equation (2), $e$ is a function of $w_{\mathrm{L}}$ and $p$ and, in turn, $C_{\mathrm{c}}$ is a function of $w_{\mathrm{L}}$ and $p$.

This extension to the Authors' treatment of double layer theory for compressibility of clays results in a logical development of the widely used, statistically based empirical relationships between compression index $C_{c}$ and liquid limit water content $w_{\mathrm{L}}$ or natural void ratio $e$.

\section{REFERENCES}

Bolt, G. H. \& Bruggenwert, M. G. M. (1976). Soil chemistry, A. Basic elements. New York: Elsevier.

Farrar, D. M. \& Coleman, G. D. (1967). The correlation of surface area with other properties of nineteen British clay soils. J. Soil Sci. 18, No. 1, 118-124.

Skempton, A. W. (1944). Notes on the compressibility of clays. J. Geol. Soc. 100, 119-135.

\section{Author's reply}

We agree with Delage and Lefebvre with respect to the existence of unequal pore sizes, clusters and domains in soils. The Paper aims to examine double layer theory with regard to remoulded clays devoid of clusters, domains and cementation. The double layer theory assumes the existence of equal separation distances and devoid of attractive forces between clay particles. It cannot be applied to the sensitive clays mentioned.

Srinivasa Murthy and Nagaraj discuss the possibility of extending the analysis for further understanding of the compressibility behaviour of natural clays. It logically relates the existing empirical relationships between the compression index and liquid limits of soils to the double layer theory. 